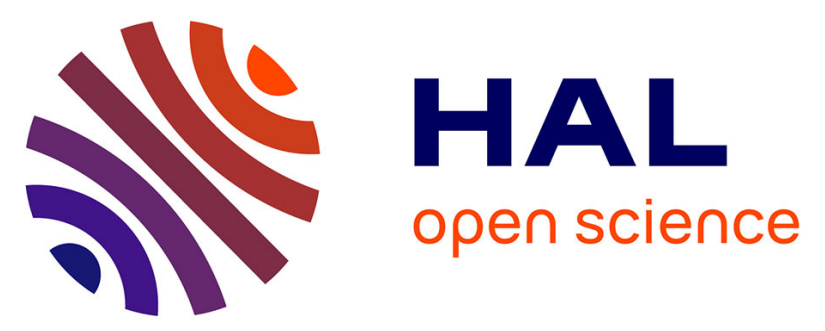

\title{
Gold nanoparticle-based localized surface plasmon immunosensor for staphylococcal enterotoxin A (SEA) detection
}

Maroua Ben Haddada, David Hu, Michèle Salmain, Lu Zhang, Chen Peng, Yi Wang, Bo Liedberg, Souhir Boujday

\section{To cite this version:}

Maroua Ben Haddada, David Hu, Michèle Salmain, Lu Zhang, Chen Peng, et al.. Gold nanoparticlebased localized surface plasmon immunosensor for staphylococcal enterotoxin A (SEA) detection. Analytical and Bioanalytical Chemistry, 2017, 409 (26), pp.6227-6234. 10.1007/s00216-017-0563-8 . hal-01585234

\section{HAL Id: hal-01585234 https://hal.sorbonne-universite.fr/hal-01585234}

Submitted on 11 Sep 2017

HAL is a multi-disciplinary open access archive for the deposit and dissemination of scientific research documents, whether they are published or not. The documents may come from teaching and research institutions in France or abroad, or from public or private research centers.
L'archive ouverte pluridisciplinaire HAL, est destinée au dépôt et à la diffusion de documents scientifiques de niveau recherche, publiés ou non, émanant des établissements d'enseignement et de recherche français ou étrangers, des laboratoires publics ou privés. 


\section{Gold Nanoparticle-Based Localized Surface Plasmon Immunosensor for}

\section{Staphylococcal Enterotoxin A (SEA) Detection}

Maroua Ben Haddada ${ }^{1,2}$, David Hu ${ }^{l}$, Michèle Salmain ${ }^{2}$, Lu Zhang ${ }^{1,3,4}$, Chen Peng ${ }^{3}$, Yi Wang ${ }^{3}$, Bo Liedberg ${ }^{3}$, Souhir Boujday ${ }^{1,4, *}$

${ }^{1}$ Sorbonne Universités, UPMC Univ Paris 6, CNRS, Laboratoire de Réactivité de Surface (LRS), 4 Place Jussieu F-75005 Paris, France

${ }^{2}$ Sorbonne Universités, UPMC Univ Paris 06, CNRS, Institut Parisien de Chimie Moléculaire (IPCM), 4 place Jussieu F-75005 Paris, France

${ }^{3}$ Centre for Biomimetic Sensor Science, School of Material Science and Engineering, Nanyang Technological University, 637553 Singapore

${ }^{4}$ MajuLab, UMI 3654, CNRS-UNS-NUS-NTU International Joint Research Unit, Singapore

Tel: +33144276001, Fax: +33144276033, souhir.boujday@upmc.fr 
ABSTRACT: We describe the engineering of stable gold nanoparticle bioconjugates for the detection of Staphylococcal enterotoxin A (SEA) using localized surface plasmon resonance (LSPR). Two types of AuNP bioconjugates were prepared by covalently attaching anti-SEA antibody (Ab) or SEA to AuNPs. This was achieved by reacting Traut's reagent with lysine residues of both proteins to generate thiol groups that bind to gold atoms on AuNp surface. These bioconjugates were characterized in-depth by absorption spectroscopy, Cryo-Transmission Electron Microscopy, Dynamic Light Scattering, and Zeta Potential measurements. Their stability over time was assessed after one year storage in the refrigerator at $4{ }^{\circ} \mathrm{C}$. Two formats of homogeneous binding assays were set up on the basis of monitoring of LSPR peak shifts resulting from the immunological reaction between the i) immobilized antibody and free SEA, the direct assay, or ii) immobilized SEA and free antibody, the competitive assay. In both formats, a correlation between the LSPR band shift and SEA concentration could be established. Though the competitive format did not meet the expected analytical performance, the direct format, which implementation was very simple, afforded a specific and sensitive response within a broad dynamic range - $\mathrm{ng} / \mathrm{mL}$ to $\mu \mathrm{g} / \mathrm{mL}$. The limit of detection (LOD) of SEA was estimated to equal $5 \mathrm{ng} / \mathrm{mL}$, which is substantially lower than the LOD obtained using quartz crystal microbalance. Moreover, the analytical performance of AuNP-Ab bioconjugate was preserved after one year of storage at $4^{\circ} \mathrm{C}$. Finally, the LSPR biosensor was successfully applied to the detection of SEA in milk samples. The homogeneous nanoplasmonic immunosensor described herein provides an attractive alternative for stable and reliable detection of SEA in the $\mathrm{ng} / \mathrm{mL}$ range and offers a promising avenue for rapid, easy to implement, and sensitive biotoxin detection.

KEYWORDS: Immunosensor, Localized Surface Plasmon Resonance, Staphylococcal Enterotoxin A, Gold nanoparticles.

\section{Electronic supplementary material}

The online version of this article (DOI) contains supplementary information, which is available to authorized users. 


\section{INTRODUCTION}

Biotoxins are species produced by microorganisms (bacteria, microalgae) for various purposes. Ingestion of food contaminated by these microorganisms causes various diseases that can, in the worst case, be fatal to humans. For instance, some strains of Staphylococcus aureus produce enteroxins that, when ingested, induce severe gastroenteritis mainly caused by the most frequently encountered enterotoxin serotype, namely staphylococcal enterotoxin A (SEA) [1,2]. Therefore, control of food safety all along the production chain is necessary to prevent food poisoning outbreaks. Classical analytical methods to detect biotoxins in food samples are generally time-consuming, require highly trained staff and sophisticated equipment and are therefore carried out in dedicated laboratories. Clearly, there is a need for rapid, specific and sensitive analytical methods to detect and quantify these biotoxins in food matrices.

The unique optical properties of gold nanoparticles (AuNPs) make them very attractive for biosensing platform development due to their localized surface plasmon resonance (LSPR) [3-5]. The extremely high extinction coefficient of these nanoparticles in the visible spectral range prompted the development of lateral flow immunoassays to visually detect staphylococcal enterotoxins [6,7]. The LSPR band of gold nanoparticles is also sensitive to local changes of the dielectric environment around them and this property led to the design of homogeneous and solid-phase assays [8-10]. Another family of AuNP-based biosensing assays relies on the large color change arising from interparticle plasmon coupling during particle aggregation and/or redispersion of the particle aggregates [11,12]. All these strategies require immobilization/conjugation of bioreceptors to AuNPs.

Various approaches have been devised to bind antibodies to gold surfaces, including gold nanoparticles. These approaches have been rationalized into 4 different concepts, namely physical adsorption, covalent binding, use of adapter/capturing molecules and combined ionic and covalent adsorption [13]. While the physical adsorption approach is straightforward, immobilization of biomolecules by covalent binding offers improved stability of the AuNP bioconjugates because of the much stronger bonds between the 
biomolecule and the supporting particle surface [14]. Furthermore, some strategies enable to conjugate antibodies to AuNP in an oriented manner taking advantage of their oligosaccharide part [15] or via their high affinity association to protein A or protein $\mathrm{G}[16]$.

Herein, we report on homogeneous, washing-free immunoassays for quantitative detection of SEA based on the change of local refractive index at the vicinity of AuNP anti-SEA antibody conjugate upon binding of the target SEA. Gold nanoparticle-antibody and -antigen bioconjugates were engineered by covalent attachment of anti-SEA antibody and SEA through sulfur-gold bonds. To this aim, SEA and antiSEA antibody were treated by Traut's reagent to convert some of their primary amines to thiol groups followed by conjugation with the AuNP. This strategy was selected because it has been shown to provide stable AuNP-protein bioconjugates [17] while maintaining a short distance between the surface of the AuNP and the bioreceptor. This was followed by in-depth characterization using absorption spectroscopy, Cryo-Transmission Electron Microscopy (CryoTEM), Dynamic Light Scattering (DLS), and zeta potential (ELS) measurements. We also assessed the stability of these bioconjugates after extended period of storage at $4{ }^{\circ} \mathrm{C}$. Two formats of homogeneous binding LSPR assays were evaluated: a direct assay where AuNP-Ab were reacted with free SEA, and a competitive assay starting from a mixture AuNP-Ab and AuNP-SEA bioconjugates followed by exposure to free SEA (see Figure 1). The second format is made possible by the multivalence of SEA that has several epitopes to be recognized by polyclonal antiSEA antibody.

\section{EXPERIMENTAL SECTION}

Materials: Sodium citrate, gold(III) chloride trihydrate, tannic acid, phosphate-buffered saline (PBS) pH=7.4 (10 mM phosphate, $2.7 \mathrm{mM} \mathrm{KCl}, 137 \mathrm{mM} \mathrm{NaCl})$, Bovine Serum Albumin (BSA), $\beta$ Lactoglobulin B from bovine milk, 2-iminothiolane hydrochloride (Traut's reagent) and staphylococcal enterotoxin A (SEA) were purchased from Sigma-Aldrich. Affinity-purified rabbit polyclonal anti-SEA antibody (anti-SEA, reference in toxin technology catalogue: LAI101) was purchased from Toxin Technology (Sarasota, FL, www.toxintechnology.com). 
Gold nanoparticles preparation and characterization: Colloidal gold nanoparticles were prepared according to the citrate / tannic acid reduction method adapted from [18] and described previously [19]. Transmission Electron Microscopy images of the gold colloids were obtained using a JEOL JEM 1011 microscope operating at an accelerating voltage of $100 \mathrm{kV}$. Cryo-Transmission Electron Microscopy images were recorded at low temperature $(93 \mathrm{~K})$ on ultrascan $2 \mathrm{~K} \mathrm{CCD}$ camera (Gatan, USA), using a LaB6 JEOL JEM 2100 (JEOL, Japan) cryo microscope operating at $200 \mathrm{kV}$ with a low dose system (Minimum Dose System, MDS). Statistical distribution was established by counting a minimum of 363 particles for TEM and of 15 particles for cryoTEM images. Dynamic Light Scattering (DLS) and zeta potential (ELS) measurements were performed using Litesizer ${ }^{\mathrm{TM}} 500$ apparatus (Anton Paar) equipped with a $658 \mathrm{~nm}$ laser operating at $40 \mathrm{~mW}$. The backscattered light collection angle was set at $90^{\circ}$. The zetapotential cuvette has a $\Omega$-shaped capillary tube. The same solutions were used for DLS and ELS measurements. Each sample was analyzed in triplicate and each measurement was an average of three 30 s runs.

Preparation of AuNPs bioconjugates: AuNP-Ab bioconjugate was engineered using a covalent approach $[20,21,17,15]$. First, Traut's reagent $(85 \mu \mathrm{M})$ was reacted with anti-SEA $(0.32 \mathrm{mg} / \mathrm{mL}, 0.55 \mu \mathrm{M})$ in 50 $\mathrm{mM}$ phosphate buffer $\mathrm{pH} 8.0$ at room temperature to generate sulfhydryl groups [22]. The thiolated antibody was separated from excess Traut's reagent by purification on a gel filtration column (Hitrap desalt $5 \mathrm{~mL}$, GE Healthcare) using PBS as eluent.

Thiolated antibody solution ( $82 \mu \mathrm{g} / \mathrm{mL}, 1.5 \mathrm{~mL}$ ) was mixed with gold nanoparticles (74.2 $\mathrm{nM}, 1.5 \mathrm{~mL})$. Then BSA was added to the bioconjugate solution at a final concentration of $0.25 \% \mathrm{w} / \mathrm{v}$ to block nonspecific binding sites [23]. Finally, the biofunctionalized AuNPs were pelleted by centrifugation at 13000g for $15 \mathrm{~min}$, washed twice to remove unbound and loosely bound $\mathrm{Ab}$ and finally re-suspended in PBS (3 mL). The concentration of antibody in the first supernatant was assayed by ELISA to estimate the number of Ab bound to AuNPs (see electronic supplementary material for experimental details and 
calculations). The same procedure was applied to prepare AuNP-SEA bioconjugate using a solution of thiolated SEA at $24 \mu \mathrm{g} / \mathrm{mL}$.

SEA immunosensing: In the direct assay, aliquots of SEA stock solution $(6 \mu \mathrm{L}$ of a $0.1 \mathrm{mg} / \mathrm{mL}$ or 1 $\mu \mathrm{g} / \mathrm{mL}$ solution in water) were serially added to the AuNP-Ab bioconjugate solution $\left(600 \mu \mathrm{L}, \mathrm{OD}_{530}=\right.$ 0.6) in a plastic cuvette. Absorption spectra of the mixtures were measured in real time (millisecond temporal resolution and $10^{-2} \mathrm{~nm}$ spectral resolution) using Insplorion XNano II instrument until equilibrium was reached $(\sim 60 \mathrm{~min})$. The same procedure was used for the competitive assay except that SEA was replaced by AuNP-SEA bioconjugate. The position of the LSPR band was plotted as a function of time using the software provided with the instrument. Error bars are determined experimentally based on a set of a minimum of three assays.

Milk sample preparation and analysis: Skimmed milk was reconstituted by dissolving $5 \mathrm{~g}$ of powder milk in $9.5 \mathrm{~mL}$ water. The $\mathrm{pH}$ of the solution was slowly brought to 4.6 by addition of $1 \mathrm{M} \mathrm{HCl}$ to precipitate casein and the suspension was centrifuged at $2550 \mathrm{~g}$ for $40 \mathrm{~min}$. The supernatant was collected and the $\mathrm{pH}$ was slowly brought to 7 by addition of $1 \mathrm{M} \mathrm{NaOH}$. The suspension was centrifuged at 10000 $\mathrm{g}$ for $20 \mathrm{~min}$ and the resulting supernatant (whey fraction) was spiked with $2 \mu \mathrm{g} / \mathrm{mL}$ SEA. Sample (300 $\mu \mathrm{L})$ was mixed with AuNP-Ab solution $\left(300 \mu \mathrm{L}, \mathrm{OD}_{530}=1\right)$ in a plastic cuvette and the absorption spectrum was recorded every 15 min for up to 95 min on a UV-Visible spectrometer (Cary 50, Varian). Mathematical determination of $\lambda_{\max }$ was done according to reference [24].

\section{Results and discussion}

Bioconjugate engineering: Citrate-capped gold nanoparticles were first characterized by absorption spectroscopy and Transmission Electron Microscopy (TEM). The resulting data, depicted in the supplementary material section (Figure S1), show a homogeneous distribution with an average particle size of $13.5 \pm 1 \mathrm{~nm}$ and an LSPR band centered at $520 \mathrm{~nm}$. The hydrodynamic diameter $\mathrm{D}_{\mathrm{H}}$ estimated by DLS was slightly larger, $18 \pm 1 \mathrm{~nm}$ and the zeta potential equal to $-45.3 \pm 1 \mathrm{mV}$ in agreement with previously published data for citrate-capped AuNP [25]. AuNP-Ab and AuNP-SEA bioconjugates were 
engineered according to an original procedure schematized in Figure 1. This coupling method ensures a covalent immobilization of the protein molecules on the surface of the gold nanoparticles by formation of Au-S bonds [26]. It also enables minimizing the distance between the transducer (AuNP) and the bioreceptor $(\mathrm{Ab})$. Indeed, the ability of gold nanoparticles to sense local refractive index changes via LSPR band shift decays rapidly with distance from the gold surface [4].

After reaction and separation of the AuNP by centrifugation, the amount of unbound $\mathrm{Ab}$ in the supernatant was found to be very small (2.2 $\mu \mathrm{g} v s 123 \mu \mathrm{g}$ in the starting solution) as assayed by ELISA (see electronic supplementary material), confirming the successful conjugation of Ab to AuNP. The final concentration of anti-SEA antibody in the AuNP-Ab solution was estimated $40 \mu \mathrm{g} / \mathrm{mL}$ and the Ab to AuNP ratio was estimated around 7 (see ESM for calculation details) which is agreement with antibody size versus nanoparticle size (see Figure S2 and reference [27]).
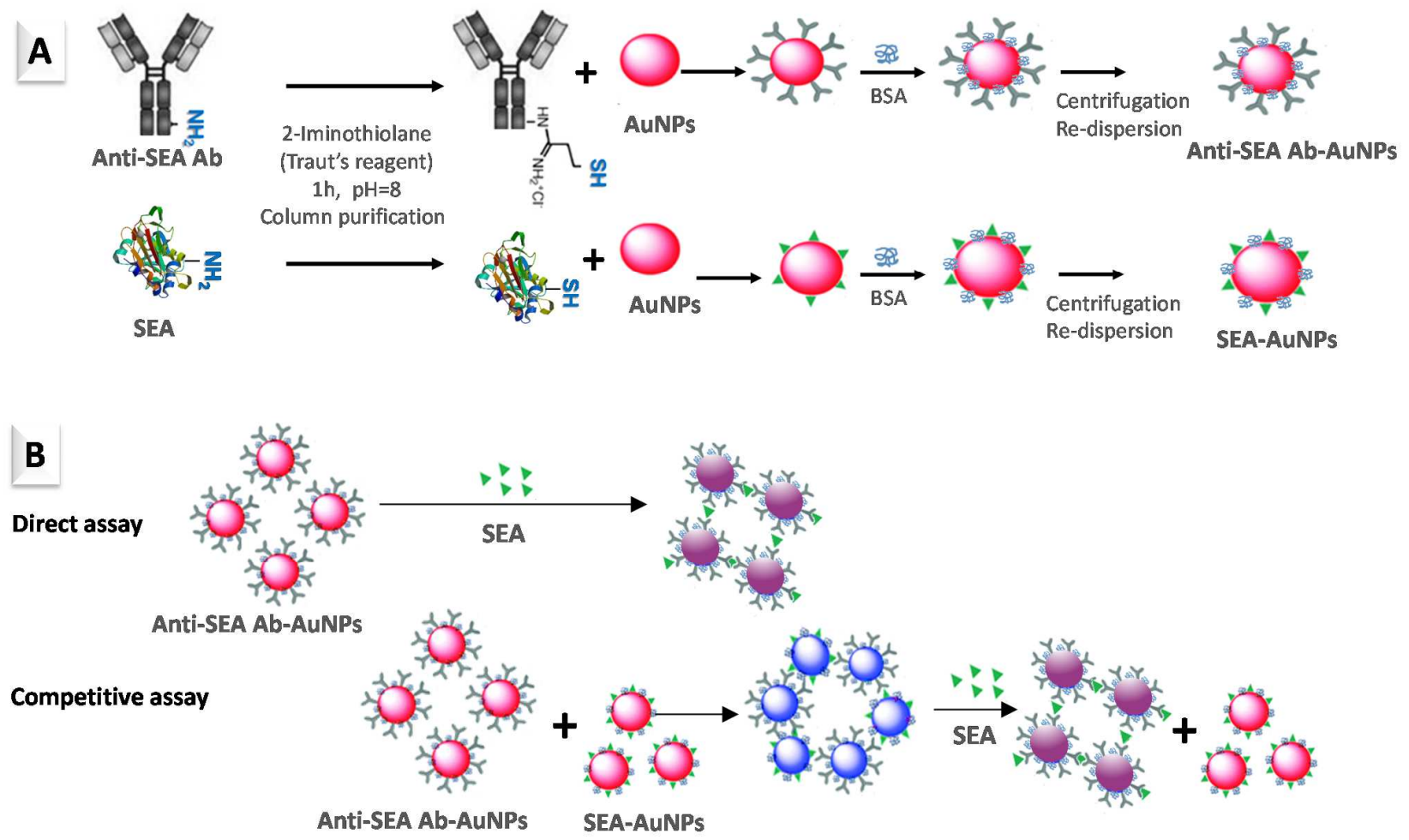

Figure 1 A: Adopted strategy for bioconjugates elaboration B: Principle of direct and competitive assays. 
Upon covalent attachment of anti-SEA Ab to AuNP, the LSPR band underwent a red-shift of $8 \mathrm{~nm}\left(\lambda_{\max }\right.$ $=528 \mathrm{~nm}$ ) and an additional shift of $1 \mathrm{~nm}\left(\lambda_{\max }=529 \mathrm{~nm}\right)$ was seen upon further blocking by BSA (Figure 2). The same trend was observed upon SEA grafting to the nanoparticles. These results are in agreement with previously published data [28]. The shape and width of the LSPR bands indicate a homogeneous distribution of the particle size that was confirmed by cryo-TEM images (see inserts in Figure 2-A). CryoTEM images also confirmed the colloidal stability of the bioconjugates as no aggregates appeared. Mathematical treatment of cryo-TEM images showed an average size of $13.3 \pm 0.7 \mathrm{~nm}(\mathrm{n}=15)$ for AuNPSEA and 14.2 $\pm 0.7(\mathrm{n}=15) \mathrm{nm}$ for AuNP-Ab. The increase of particles size due to the grafted proteins could not be seen by cryoTEM but was evidenced by DLS measurements as the hydrodynamic diameter of AuNP-Ab and AuNP-SEA increased to $76 \pm 1$ and $54.6 \pm 0.5 \mathrm{~nm}$, respectively (Figure 2; table S1). As for citrate-coated gold nanoparticles, the hydrodynamic diameter is likely overestimated as the resulting values are larger than expected from geometrical considerations. Indeed, considering the IgG structure (ref [29] and Figure S2), the diameter of gold nanoparticles covered by a monolayer of chemisorbed antibodies should be around $50 \mathrm{~nm}$ maximum. The zeta potential of AuNP in PBS pH 7.4 also increased from $-45.3 \mathrm{mV}$ to $-18.9 \mathrm{mV}$ after conjugation of $\mathrm{Ab}$ (see Figure 2-B and Table $\mathrm{S} 1$ ) in agreement with previously reported data [30]. The increase was even larger for AuNP-SEA bioconjugate, $-6.3 \mathrm{mV}$. If the surface of gold particles is fully covered with proteins, the net charge of the conjugate is expected to be close to that of the protein itself [31]. The calculated isoelectric point (pI) of SEA is 6.6 according to the Expasy database, meaning that the protein should be slightly negatively charged at $\mathrm{pH} 7.4$ in accordance with the Z-potential value given above. The $\mathrm{pI}$ of rabbit anti-SEA IgG is unknown, but the purification of rabbit IgG from serum by anion exchange chromatography was previously shown to afford two IgG fractions with pI 5.65-8.7 and 5.5 - 7.1, respectively [32]. The Z-potential value of the AuNP-Ab conjugate indicates that this antibody is more negatively charged than SEA at $\mathrm{pH} 7.4$, meaning that its $\mathrm{pI}$ is probably below 6 , that is in the lower range of the intervals given above. To estimate the Z-potential of 
the anti-SEA Ab, we measured the zeta-potential of a rabbit IgG. The resulting value, $-16.1 \mathrm{mV}$, was in agreement with the zeta potential measured for AuNP-Ab bioconjugate.
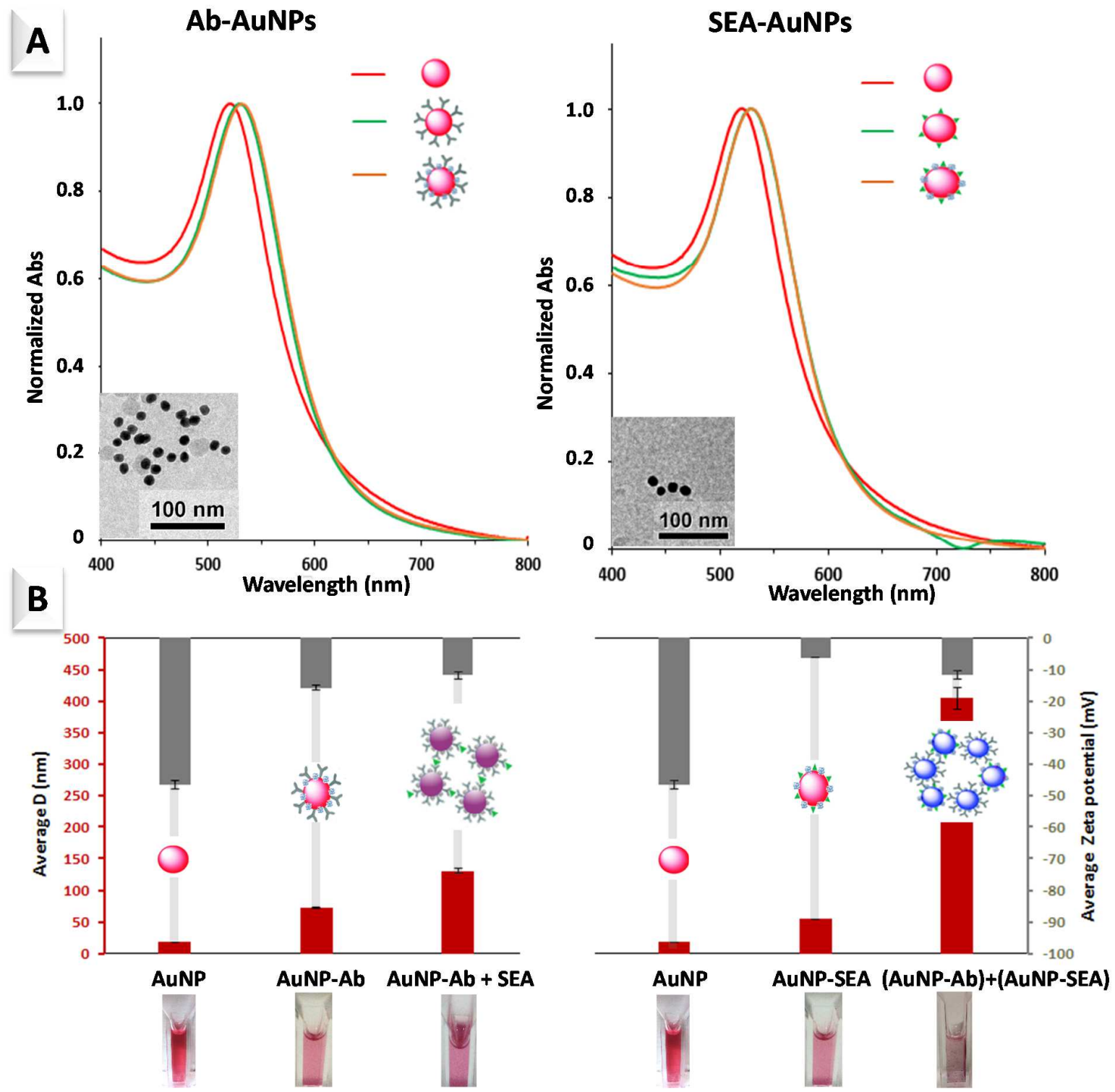

Figure 2 A: LSPR band change upon conjugation of anti-SEA Ab (left) and SEA (right) to AuNPs and subsequent BSA backfilling. The inserts show representative cryo-TEM images of AuNP-Ab and AuNP-SEA bioconjugates. B: hydrodynamic diameter and zeta potential of citrate-coated AuNP, AuNP conjugates and mixtures of AuNP-Ab and free SEA or AuNP-SEA conjugate $(5 \mu \mathrm{g} / \mathrm{mL})$. Images or the corresponding solutions are added below.

In a preliminary experiment, the position of the LSPR band of the colloidal solution of AuNP-Ab was monitored over time upon addition of SEA $(1 \mu \mathrm{g} / \mathrm{mL})$. Progressive shift of the LSPR band to the red $\Delta \lambda$ $=5 \mathrm{~nm}$ was seen in approx. $1 \mathrm{~h}$ (Figure 3A). Further additions of SEA led to further shifts of the LSPR 
band which reached a total shift of $\Delta \lambda=11 \mathrm{~nm}$ upon exposure to $3 \mu \mathrm{g} / \mathrm{mL}$ SEA; no further shift was observed for higher SEA concentrations (Figure 3A and insert therein). In parallel, the hydrodynamic diameter reached $131 \mathrm{~nm}$ and the Z-potential shifted form $-18.9 \mathrm{mV}$ to $-11.8 \mathrm{mV}$ (Figure $2 \mathrm{~B}$ and table S1).

The same experiment was carried out with AuNP-SEA instead of free SEA. Similarly, progressive shift of the LSPR band to the red was noticed reaching $\Delta \lambda=7 \mathrm{~nm}$ at saturation (Figure 3B). In this case, a perceptible change in color from pink to purple was observed (Figure 2B, right) as well as a significant increase of the absorbance between 600 and $700 \mathrm{~nm}$ (Figure S3) and a measured average $\mathrm{D}_{\mathrm{H}}$ of $404 \mathrm{~nm}$ by DLS (Figure 2B and table S1). All these data are consistent with the formation of aggregates resulting from interparticle crosslinking through $\mathrm{Ab} / \mathrm{Ag}$ interactions. In the envisioned competitive detection assay (see Figure 1), the presence of SEA in the milieu was expected to lead to a "de-aggregation" by breaking the $\mathrm{Ab} / \mathrm{Ag}$ cross-linking through a competition between free SEA molecules and AuNP-SEA. Unfortunately, addition of free SEA to the mixture of AuNP-Ab and AuNP-SEA did not break the Ab/Ag cross-linking nor lead to particle dispersion as expected [33,34]. Instead, further shifts of the LSPR band to the red occurred $(\Delta \lambda=2 \mathrm{~nm}$ for $[\mathrm{SEA}]=1 \mu \mathrm{g} / \mathrm{mL}$ and $\Delta \lambda=3.7 \mathrm{~nm}$ for [SEA] $=2 \mu \mathrm{g} / \mathrm{mL})$ possibly because all the available antibody binding sites were not occupied by the antigen from AuNP-SEA in the first place. Extension of the incubation time or change of the AuNP-Ab / AuNP-SEA proportion did not improve the results. We thus conclude that the competitive assay format is not feasible for SEA detection. In what follows, we explore the efficiency of AuNP-Ab in the one-step colorimetric assay of SEA in the direct format depicted in Figure 1.

Optimizing the homogeneous assay of SEA: Since the Insplorion XNano II instrument employed for the LSPR measurements displays high spectral resolution $(0.01 \mathrm{~nm})$, we anticipated that much lower band shifts corresponding to lower analyte concentrations could be monitored. Real-time monitoring of the LSPR band position was undertaken upon addition of increasing amounts of SEA in the range 10 to 250 $\mathrm{ng} / \mathrm{mL}$ (Figure 3C). A progressive shift of the LSPR band was observed and a dose-response curve was 
established by plotting the band shift $\Delta \lambda$ measured after stabilization (approx. $1 \mathrm{~h}$ ) versus the concentration of analyte (Figure 3D). We also used DLS to explore whether it could provide analytical data on SEA detection. DLS results are shown in the supplementary material section Figure S4. Though the addition of SEA to the bioconjugate led to a perceptible increase in the hydrodynamic diameter starting from low SEA concentrations $\left(\Delta \mathrm{D}_{\mathrm{H}}=50 \mathrm{~nm}\right.$ for $\left.10 \mathrm{ng} / \mathrm{mL}\right)$ no consistent change could be observed upon adding higher amounts of SEA; the average hydrodynamic diameter was barely changed after the first addition. 

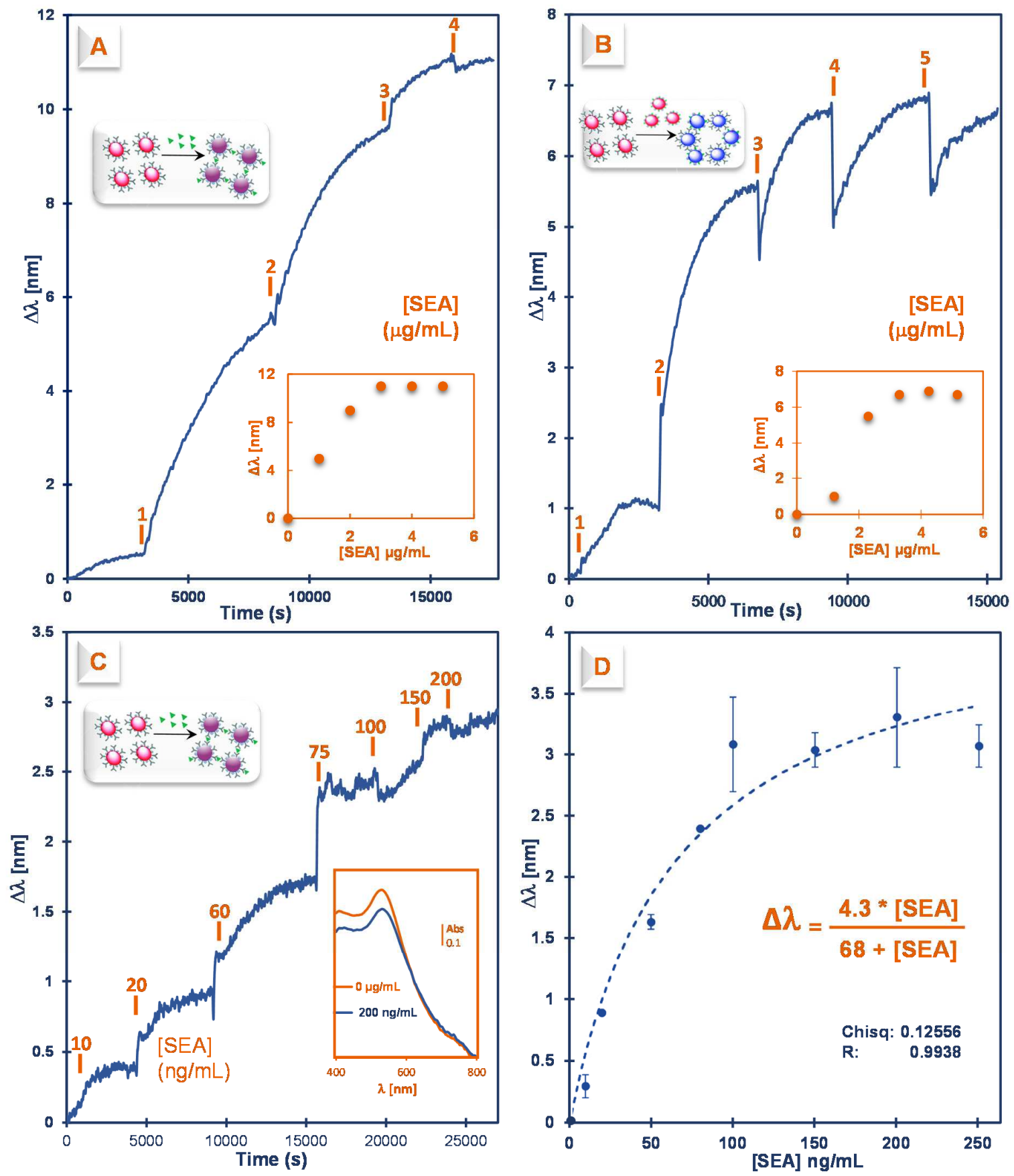

Figure 3 A and B: Examples of LSPR curves obtained by incubating AuNP-Ab conjugate with increasing concentrations of free SEA in the 1 to $4 \mu \mathrm{g} / \mathrm{mL}$ range (A) and AuNP-SEA (B), the inserts show the dose-response curves obtained by plotting the LSPR band shift $\Delta \lambda$ as a function of SEA concentration measured after ca. $1 \mathrm{~h}$ incubation. C: Example of LSPR curve obtained by incubating AuNP-Ab conjugate with increasing concentrations of free SEA in the ng/mL range. The insert shows the LSPR peak for the initial and final AuNP-Ab conjugate. D: Dose-response curve obtained by plotting the LSPR band shift $\Delta \lambda$ from a set of experiments similar to $\mathbf{C}$ as a function of SEA concentration in the 0 to $250 \mathrm{ng} / \mathrm{mL}$ range measured after 50 min incubation, average data from three experiments.

Mathematical fitting of the dose-response curve in Figure 3D using the Langmuir isotherm equation gave an apparent dissociation constant $\mathrm{K}_{\mathrm{D}}$ of $68 \pm 13 \mathrm{ng} / \mathrm{mL}=2.5 \pm 0.5 \mathrm{nM}$. Therefore, anti-SEA 
maintained a high affinity for its target after conjugation. The limit of detection was calculated to equal 5 $\mathrm{ng} / \mathrm{mL}=0.2 \mathrm{nM}$ from $3 \mathrm{x}$ the response of a blank sample $(\Delta \lambda=0.1 \mathrm{~nm})$. The dynamic range was widened and the assay sensitivity was improved as compared to our recently reported piezoelectric immunosensor for SEA [35,36]; In the direct assay format, using the same antibody reagent and a temperature controlled quartz crystal microbalance platform, the LOD was 4 times higher, $20 \mathrm{ng} / \mathrm{mL}$. We expect that the limit of detection may be further decreased by replacing the gold nanospheres by nonspherical gold nanoparticles that show higher refractive index sensitivity [4]. It is important to note at this stage that the presence of a plateau in dose-response curve observed in Figure 2D is surprising if we consider the sensor response at higher SEA concentration plot in Figure 2D with a higher saturation coverage. This might look controversial and our main hypothesis to explain this observation is that there would be two working ranges of the sensor: In the first one, at low SEA concentrations (up to $250 \mathrm{ng} / \mathrm{mL}$ ), we measure a small shift upon SEA binding to AuNP-Ab bioconjugates. Within this format, we reach a first plateau in the detection mode around $3 \mathrm{~nm}$. At higher SEA concentrations (above $1 \mu \mathrm{g} / \mathrm{mL}$ ) the shift is higher and possibly ascribable to AuNP-Ab cross-linking through simultaneous recognition of SEA molecules by antibodies belonging to different bioconjugates; a sort of self-assembly of colloids through $\mathrm{Ab} / \mathrm{Ag}$ interactions. We envision several experiments to explore this hypothesis, including cryoTEM analysis at different analyte concentrations in upcoming work.

The same binding experiment performed by addition of 100 up to $2300 \mathrm{ng} / \mathrm{mL}$ bovine $\beta$-lactoglobulin (a protein present in high concentration in the whey fraction of cow's milk) to the colloidal solution of AuNP-Ab did not lead to any significant change of the LSPR band (Figure S5), indicating that previous band shifts were indeed related to the highly selective binding of SEA to anti-SEA conjugated to AuNP.

We assessed the long term stability of the AuNP-Ab bioconjugate. The same batch of AuNP-Ab bioconjugate, stored in the refrigerator at $4^{\circ} \mathrm{C}$ for one year was used to reproduce the LSPR experiments for direct detection of SEA. The suspension was visibly stable under storage period and the UV-Visible spectra were identical to the original ones confirming that no aggregation occurred (Figure S6). Note that 
when antibodies are simply physisorbed on gold nanoparticles, aggregation occurred within less than 2 weeks. The results of LSPR assay of SEA after extended storage are shown in the supplementary material, Figure S6. The response of the sensor was similar to the freshly prepared bioconjugate showing a remarkable stability over time paving the way for a commercial use of the developed biosensor.

Finally, the nanoplasmonic immunosensor was applied to the detection of SEA spiked in milk. The absorption spectra obtained upon mixing AuNP-Ab with milk samples (whey fraction) spiked with SEA for increasing incubation time ( 0 to $90 \mathrm{~min}$ ) are shown in Figure 4. These spectra were obtained using benchtop UV-Visible spectrometer, nevertheless an obvious shift is observed upon incubation with spiked compared to unspiked milk: The unspiked milk sample gave a $\lambda_{\max }=531 \mathrm{~nm}$ whereas the milk sample spiked with $1 \mu \mathrm{g} / \mathrm{mL}$ SEA gave a $\lambda_{\max }=535 \mathrm{~nm}$ in good agreement with data obtained in buffer.
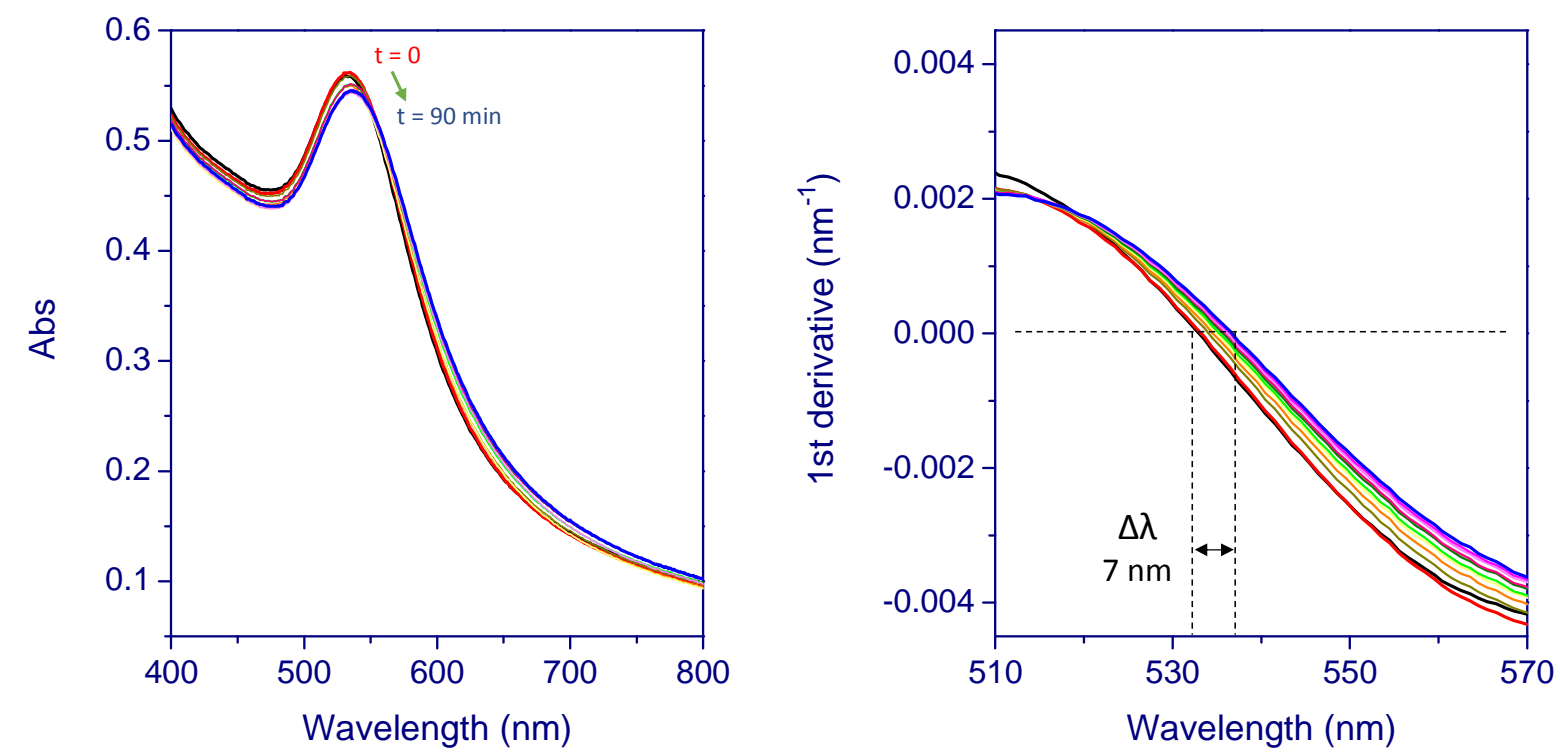

Figure 4. Left: LSPR curves measured upon incubation of AuNP-Ab conjugate with unspiked milk (black trace) and at increasing incubation time (from 0 to $90 \mathrm{~min}$ ) with $1 \mu \mathrm{g} / \mathrm{mL}$ SEA in milk (red to blue curves). Right: The first derivatives of the LSPR curves.

To improve the precision of this measurement, we determined $\lambda_{\max }$ following the zero value of the first derivatives of these spectra also shown (in Figure 4). This methods described in reference [24] allowed 
us to measure a $7 \mathrm{~nm}$ shift at equilibrium. Following these promising preliminary results in milk, the analytical performances of these gold nanoparticle-antibody bioconjugates in food matrices will be deeply investigated in future work.

\section{CONCLUSIONS}

Stable gold nanoparticle-antibody bioconjugate (AuNP-Ab) was engineered by covalently linking antiSEA antibody to citrate-capped gold nanoparticles using Traut's reagent. This bioconjugate was studied in-depth by several characterization techniques and was remarkably stable after one year storage in the refrigerator at $4^{\circ} \mathrm{C}$. Two formats of homogeneous binding assays of Staphylococcal enterotoxin A (SEA) by localized surface plasmon resonance (LSPR) were set up based on a direct assay strategy, in which AuNP-Ab was reacted with SEA, and a competitive assay starting from a mixture of AuNP-Ab and AuNPSEA bioconjugates. Correlation between plasmon shifts and SEA concentration was established when the anti-SEA antibody conjugated to AuNP was mixed with SEA in the free form or conjugated to AuNP. In the case of mixtures AuNP-Ab and AuNP-SEA bioconjugates (competitive format), a red shift of the plasmon peak along with nanoparticle aggregation were observed. However, addition of free SEA to the mixture of AuNP-Ab and AuNP-SEA did not lead to particle dispersion suggesting that this competitive format is not feasible for SEA assay. The one-step LSPR assay of SEA with AuNP-Ab bioconjugate afforded remarkable analytical performances at the $\mathrm{ng} / \mathrm{mL}$ level. SEA was assayed in both the $\mathrm{ng} / \mathrm{mL}$ and $\mu \mathrm{g} / \mathrm{mL}$ working ranges with a calculated limit of detection (LOD) of $5 \mathrm{ng} / \mathrm{mL}(0.2 \mathrm{nM})$. Moreover, the response of the sensor after one year storage at $4{ }^{\circ} \mathrm{C}$ was similar to the freshly prepared bioconjugate showing a remarkable stability over time. Preliminary assays in spiked milk confirmed the efficiency of these bioconjugates for SEA biosensing in food matrix. The nanoplasmonic immunosensor described herein requires rather simple optical equipment and straightforward manipulations, and provides an 
attractive alternative to more bulky and expensive approaches for rapid and sensitive detection of SEA and other toxins.

\section{ACKNOWLEDGEMENT}

We would like to thank the DIM Analytics and Region Ile-de-France for M. Ben Haddada PhD scholarship. We also thank Anton Paar for the access to Litesizer ${ }^{\mathrm{TM}} 500$ apparatus. This work was supported by the iFood initiative Nanyang Technological University, by the French-Singaporean PHC Merlion program (grant 5.03.15) and by the ANR-FWF program (grant ANR-15-CE29-0026).

\section{Compliance with ethical standards}

\section{Conflict of interest}

The authors declare that they have no competing interests. 


\section{REFERENCES}

1. Hennekinne J-A, De Buyser M-L, Dragacci S (2012) Staphylococcus aureus and its food poisoning toxins: characterization and outbreak investigation. FEMS Microbiol Rev 36:815-836

2. Le Loir Y, Baron F, Gautier M (2003) Staphylococcus aureus and food poisoning. Genet Mol Res 2 (1):63-76

3. Jans H, Huo Q (2012) Gold nanoparticle-enabled biological and chemical detection and analysis. Chem Soc Rev 41 (7):2849-2866. doi:10.1039/C1CS15280G

4. Mayer KM, Hafner JH (2011) Localized Surface Plasmon Resonance Sensors. Chem Rev 111 (6):38283857. doi:10.1021/cr100313v

5. Sepulveda B, Angelome PC, Lechuga LM, Liz-Marzan LM (2009) LSPR-based nanobiosensors. Nano Today 4 (3):244-251. doi:10.1016/j.nantod.2009.04.001

6. Rong-Hwa S, Shiao-Shek T, Der-Jiang C, Yao-Wen H (2010) Gold nanoparticle-based lateral flow assay for detection of staphylococcal enterotoxin B. Food Chem 118 (2):462-466. doi:10.1016/j.foodchem.2009.04.106

7. Wang WB, Liu LQ, Xu LG, Kuang H, Zhu JP, Xu CL (2016) Gold-Nanoparticle-Based Multiplexed Immunochromatographic Strip for Simultaneous Detection of Staphylococcal Enterotoxin A, B, C, D, and E. Particle \& Particle Systems Characterization 33 (7):388-395. doi:10.1002/ppsc.201500219

8. Englebienne P (1998) Use of colloidal gold surface plasmon resonance peak shift to infer affinity constants from the interactions between protein antigens and antibodies specific for single or multiple epitopes. Analyst 123 (7):1599-1603. doi:10.1039/A804010I

9. Mayer KM, Lee S, Liao H, Rostro BC, Fuentes A, Scully PT, Nehl CL, Hafner JH (2008) A LabelFree Immunoassay Based Upon Localized Surface Plasmon Resonance of Gold Nanorods. ACS Nano 2 (4):687-692. doi:10.1021/nn7003734

10. Nath N, Chilkoti A (2004) Label-Free Biosensing by Surface Plasmon Resonance of Nanoparticles on Glass: Optimization of Nanoparticle Size. Anal Chem 76 (18):5370-5378. doi:10.1021/ac049741z

11. Liu XH, Wang Y, Chen P, Wang YS, Mang JL, Aili D, Liedberg B (2014) Biofunctionalized Gold Nanoparticles for Colorimetric Sensing of Botulinum Neurotoxin A Light Chain. Anal Chem 86 (5):23452352. doi:10.1021/ac402626g

12. Zhao W, Brook MA, Li Y (2008) Design of Gold Nanoparticle-Based Colorimetric Biosensing Assays. ChemBioChem 9 (15):2363-2371. doi:10.1002/cbic.200800282

13. Montenegro J-M, Grazu V, Sukhanova A, Agarwal S, de la Fuente JM, Nabiev I, Greiner A, Parak WJ (2013) Controlled antibody/(bio-) conjugation of inorganic nanoparticles for targeted delivery. Adv Drug Del Rev 65 (5):677-688. doi:http://dx.doi.org/10.1016/j.addr.2012.12.003

14. Wang Z, Ma L (2009) Gold nanoparticle probes. Coord Chem Rev 253 (11-12):1607-1618. doi:http://dx.doi.org/10.1016/j.ccr.2009.01.005

15. Wang X, Mei Z, Wang Y, Tang L (2017) Comparison of four methods for the biofunctionalization of gold nanorods by the introduction of sulfhydryl groups to antibodies. Beilstein Journal of Nanotechnology 8:372-380. doi:10.3762/bjnano.8.39

16. Boujday S, Bantegnie A, Briand E, Marnet P-G, Salmain M, Pradier C-M (2008) In-Depth Investigation of Protein Adsorption on Gold Surfaces: Correlating the Structure and Density to the Efficiency of the Sensing Layer. J Phys Chem B 112 (21):6708-6715

17. Wang X, Mei Z, Wang Y, Tang L (2015) Gold nanorod biochip functionalization by antibody thiolation. Talanta 136:1-8. doi:http://dx.doi.org/10.1016/j.talanta.2014.11.023

18. Slot JW, Geuze HJ (1984) A method to prepare isodisperse colloidal gold sols in the size range 3-17 NM. Ultramicroscopy 15 (4):383. doi:http://dx.doi.org/10.1016/0304-3991(84)90144-X

19. Ben Haddada M, Huebner M, Casale S, Knopp D, Niessner R, Salmain M, Boujday S (2016) Gold Nanoparticles Assembly on Silicon and Gold Surfaces: Mechanism, Stability, and Efficiency in Diclofenac Biosensing. J Phys Chem C 120:29302-29311 
20. Dixit CK, Kaushik A (2012) Nano-structured arrays for multiplex analyses and Lab-on-a-Chip $\begin{array}{llllll}\text { applications. } & \text { Biochem } & \text { Biophys } & \text { Res } 316-320 .\end{array}$ doi:http://dx.doi.org/10.1016/j.bbrc.2012.02.018

21. Sule Shantanu V, Sukumar M, Weiss Iv William F, Marcelino-Cruz Anna M, Sample T, Tessier Peter M (2011) High-Throughput Analysis of Concentration-Dependent Antibody Self-Association. Biophys J 101 (7):1749-1757. doi:http://dx.doi.org/10.1016/j.bpj.2011.08.036

22. Hermanson GT (2008) Chapter 1 - Functional Targets. In: Bioconjugate Techniques (Second Edition). Academic Press, New York, pp 1-168. doi:http://dx.doi.org/10.1016/B978-0-12-370501-3.00001-1

23. Hermanson GT (2007) Chapter 24 - Preparation of Colloidal Gold-Labeled Proteins. In: Bioconjugate

Techniques (Second Edition). Academic Press, New York, pp 924-935. doi:http://dx.doi.org/10.1016/B978-0-12-370501-3.00024-2

24. Chen P, Liedberg B (2014) Curvature of the Localized Surface Plasmon Resonance Peak. Anal Chem 86 (15):7399-7405. doi:10.1021/ac500883x

25. Xia H, Xiahou Y, Zhang P, Ding W, Wang D (2016) Revitalizing the Frens Method To Synthesize Uniform, Quasi-Spherical Gold Nanoparticles with Deliberately Regulated Sizes from 2 to $330 \mathrm{~nm}$. Langmuir 32 (23):5870-5880. doi:10.1021/acs.langmuir.6b01312

26. Sule Shantanu V, Sukumar M, Weiss William F, Marcelino-Cruz Anna M, Sample T, Tessier Peter M (2011) High-Throughput Analysis of Concentration-Dependent Antibody Self-Association. Biophys J 101 (7):1749-1757. doi:10.1016/j.bpj.2011.08.036

27. Sperling RA, Parak WJ (2010) Surface modification, functionalization and bioconjugation of colloidal inorganic nanoparticles. Philosophical Transactions of the Royal Society A: Mathematical, Physical and Engineering Sciences 368 (1915):1333-1383. doi:10.1098/rsta.2009.0273

28. Thobhani S, Attree S, Boyd R, Kumarswami N, Noble J, Szymanski M, Porter RA (2010) Bioconjugation and characterisation of gold colloid-labelled proteins. J Immunol Methods 356 (1-2):6069. doi:10.1016/j.jim.2010.02.007

29. Klein JS, Gnanapragasam PNP, Galimidi RP, Foglesong CP, West AP, Bjorkman PJ (2009) Examination of the contributions of size and avidity to the neutralization mechanisms of the anti-HIV antibodies b12 and 4E10. Proceedings of the National Academy of Sciences 106 (18):7385-7390. doi:10.1073/pnas.0811427106

30. Hinterwirth H, Stübiger G, Lindner W, Lämmerhofer M (2013) Gold Nanoparticle-Conjugated AntiOxidized Low-Density Lipoprotein Antibodies for Targeted Lipidomics of Oxidative Stress Biomarkers. Anal Chem 85 (17):8376-8384. doi:10.1021/ac401778f

31. Yang WJ, Trau D, Renneberg R, Yu NT, Caruso F (2001) Layer-by-layer construction of novel biofunctional fluorescent microparticles for immunoassay applications. J Colloid Interface Sci 234 (2):356-362. doi:10.1006/jcis.2000.7325

32. Geoghegan WD (1988) The effect of three variables on adsorption of rabbit IgG to colloidal gold. Journal of Histochemistry \& Cytochemistry 36 (4):401-407. doi:10.1177/36.4.3346540

33. Liu X, Huo Q (2009) A washing-free and amplification-free one-step homogeneous assay for protein detection using gold nanoparticle probes and dynamic light scattering. J Immunol Methods 349 (1-2):3844. doi:10.1016/j.jim.2009.07.015

34. Tsai CS, Yu TB, Chen CT (2005) Gold nanoparticle-based competitive colorimetric assay for detection of protein-protein interactions. Chem Commun (34):4273-4275. doi:10.1039/b507237a

35. Salmain M, Ghasemi M, Boujday S, Pradier CM (2012) Elaboration of a reusable immunosensor for the detection of staphylococcal enterotoxin A (SEA) in milk with a quartz crystal microbalance. Sens Actuator B-Chem 173:148-156. doi:10.1016/j.snb.2012.06.052

36. Salmain M, Ghasemi M, Boujday S, Spadavecchia J, Techer C, Val F, Le Moigne V, Gautier M, Briandet R, Pradier CM (2011) Piezoelectric immunosensor for direct and rapid detection of staphylococcal enterotoxin A (SEA) at the ng level. Biosensors \& Bioelectronics 29 (1):140-144. doi:10.1016/j.bios.2011.08.007 
